\title{
Lab Notebooks: Efficient Grading and Effective Learning
}

\author{
Jonathan E. Moore ${ }^{1}$ and Theresa W. Lynn ${ }^{2}$ \\ ${ }^{1}$ Pomona College, Biology, $175 \mathrm{~W}^{\text {th }}$ St, Claremont CA 91711 USA \\ ${ }^{2}$ Harvey Mudd College, Physics, 301 Platt Blvd, Claremont CA 91711 USA \\ (jon.moore@pomona.edu; lynn@hmc.edu)
}

While critical to good scientific training, effectively teaching good lab notebook skills is challenging, and subsequently grading the notebooks is often a chore. We have developed a novel exercise and discussion for the first day of lab, and use a malleable grading approach that rapidly teaches students good lab notebook skills while keeping the grading time at approximately a minute per student per lab session.

Keywords: lab notebooks, teaching labs

\section{Introduction}

Keeping a good lab notebook is one of the skills often taught in science labs which is both critical for a career in science and very broadly applicable. While easy to enumerate a lengthy useful set of items that a lab notebook should contain, it is often harder to convey briefly and effectively the goals of a notebook. Additionally, grading lab notebooks can be sufficiently time intensive to be a prohibitive exercise in large classes. We outline here a classroom exercise and grading approach to address these issues.

\section{Classroom Exercise}

We have developed and refined a 20 to 25 minute activity involving Legos ${ }^{\circledR}$ to teach how to keep an effective lab notebook. Detailed lecture notes can be found in the "Notes for the Instructor" section. This activity has a number of merits.

First, it is active and memorable and fun. Everyone likes Legos ${ }^{\circledR}$. The activity is far more exciting than a bunch of rules as to how to keep a good lab notebook, though this exercise does actually give some rules.

It is quickly accessible. One of us has seen approximately 500 students do this activity, and only one was clearly not familiar with Legos ${ }^{\circledR}$. She looked at what someone else was doing and of course picked it up right away.

The students as a group provide most of the strategies to keep effective lab notebooks, which is mildly empowering.
By emphasizing the goals achieved by keeping a good lab notebook, it encourages students to be thoughtful. It also gives them liberty to find alternative ways to achieve those goals.

\section{Grading Approach Mechanics}

At the end of each session, the lab notebooks are collected and returned graded between 18 and 42 hours later at the beginning of their next lecture class for the same course. Instead of grading them thoroughly, only three to six predetermined and undisclosed items are sought and graded. This usually takes less than one minute per notebook, and if it takes more than two, then the notebook is deemed poorly organized and the points for the ungraded items are not earned. At the beginning, a week's notebook assignment is worth just half of what it is worth at the end. Additionally, graded items will be repeated as the course progresses.

In the introductory cell biology class in which this is used, examples of items to be graded include:

- key data such as a final yield

- a well formatted data table

- a graph with labeled axes and units

- repetitious data that is efficiently mapped to slight differences in procedure

- clear directions to digital data

- a complete procedure or a reference to another source with the procedure

- dilutions calculations

- concentrations of key reagents that are specific to their experiment 
- a meaningful title or introduction that conveys the point of what was to being done

- a hypothesis when appropriate

- conclusions

- a complete table of contents and labels on the experiments, such as page numbers or dates, that allow the table of contents to be useful.

This list is far from comprehensive, and while many items here might be relevant to your course, others will surely be not.

\section{Grading Approach Advantages}

It is effective. While it stresses some students at first to not be told exactly everything to do, they learn. Despite many grades of 50 to 70 in the first weeks, the last two times I have used this approach in Intro Cell Bio, 94\% of students had a final score of 80 or better on their notebooks. For the scores of 85 and 90 , those fractions are $89 \%$ and $64 \%$, respectively.

Much of the power of this approach is the frequent feedback. Before we started this, most professors in this course would collect notebooks halfway through the semester. Many students' grades after this first collection were $50 \%$ and $60 \%$, and while they would improve upon the next grading, medians for a course were rarely over $80 \%$. It was demoralizing to many.

While one does need the discipline to grade notebooks quickly and promptly, grading is fast and again typically averages only one minute per student. Using the other approach would eat up often an entire day or more of spring break for a class of 30 students.

While it would likely be better to grade them thoroughly after every class, this approach allows for very fast feedback. And this abbreviated way also emphasizes the need for effective organization and terseness.

This approach also incentivizes and teaches keeping your lab notebook in real time, which is how one needs to keep a good lab notebook. Waiting leads to forgetfulness. The students learn real-time skills, like anticipating how their data should be organized before collecting it and otherwise thinking ahead.

This grading mimics the way notebooks are often used. Rarely are large sections of notebooks read from beginning to end. Often, one is looking for a critical piece of data, a concentration, the order of a few steps in a procedure, or the like.

\section{Working Together}

Obviously, one could adopt either the Lego $\AA$ exercise or the notebook grading approach independent of the other. The frequent grading of notebooks allows students to learn iteratively what makes for a good notebook, which helps them achieve the goals of a notebook emphasized in the Lego ${ }^{\circledR}$ lesson. Ultimately, these two parts work very well together.

\section{Materials}

We distribute about 15-18 assorted Legos ${ }^{\circledR}$ per student in small paper bags. Additionally, they already have a lab notebook.

\section{Notes for the Instructor}

\section{Legos ${ }^{\circledR}$ Activity on Keeping a Lab Notebook}

The total time is 20 to 25 minutes. Instructions are preceded by -'s. Things to write on the board are [bracketed].

\section{Introduction (1 minute)}

- Pass out to each student a paper bag with 15-18 assorted Legos $\AA$.

- Introduce task orally and written on the board in complete sentences.

[Build a Legos ${ }^{\circledR}$ staircase using all of the blocks provided. The staircase must stand on its own, and each step must be one block high. Document your work. You have three minutes.]

By writing in complete sentences, I am purposefully trying to suggest a strategy that is often inefficient for lab notebooks. I am also purposefully writing by hand, so that bad handwriting is on their mind. - Tell them if they do not have paper, they can use the back page of their lab notebook; act like you just thought of this.

\section{Building and Documenting (5 minutes)}

- Warn the class when 1 minute remains of the original three. At the 3-minute mark, announce that time is up but you will give students an extra minute. Cut off work after a total of 4 minutes.

Walk around while they do this. Make polite short comments like "creative" or "nice." Remind them of the second part of the task, "documenting your work." Increasingly, my students either just stop after building the staircase, like documenting it is beneath them or they forgot, or alternatively they obsess and ask what it means to document their work. I usually say "to record the process of making the staircase" or "document what you did." I purposefully don't use the word "write." I've already restricted their mindset enough by mentioning paper.

- Ask students to disassemble their creations and put all the materials (including notes) back into the paper bag. While they do this, thank them and compliment them on their lovely creations.

This is both nice and a stalling tactic. I want them to have disassembled the staircases most of the way before announcing the next step. 


\section{Rebuilding (4 minutes)}

-Have students exchange paper bags and notes with someone at least two desks away.

-Instruct them to follow their classmates' notes and attempt to rebuild the classmates' Legos ${ }^{\circledR}$ staircases. Give 3-4 minutes for this activity.

If students are relatively successful, they may want to spend a minute checking their reconstruction with the original creators.

Mini Lecture (3 minutes)

-Before circling back to the Legos ${ }^{\circledR}$ exercise, mention the reasons for keeping a lab notebook and the contexts in which one might keep a lab notebook. Key points:

[Why Keep a Lab Notebook?]

1) [What reasoning drove the actions? (intro or informative title)]

Otherwise, later one struggles to understand why things were done. Each new part should have either a short intro or a very informative title.

\section{2) [So someone can repeat what you did]}

This enables someone (other or self) to retrace your steps later on. What did I do? If there is a protocol, where is it and how did I deviate from it. If the final product is material, where did I put it? Who is the "someone"?

3) [A central organized place for data and its interpretation]

Data can be elsewhere, but a process to find it needs to be able to be started in a notebook. Tables are useful.

4) [Provide written evidence of what was done]

Notebooks are valuable for patent and fraud cases

\section{5) [Generally useful]}

Notebooks are not just for science. Detectives keep notebooks. When I needed to care for a pool, I kept a notebook.

-State that the first 3 provide much of the general outline for a lab notebook each lab day.

\section{Class Discussion (5-8 minutes)[Notebook Strategies]}

-Ask what worked well with the Legos ${ }^{\circledR}$ exercise.

Write this list on the board. If this totally or mostly failed, ask alternatively what didn't work and try to turn most of these suggestions into "do's" instead of "donot's." If these don't come up, make them come up.

\section{1) [Write in Real Time]}

Forgetfulness sets in quickly. Often more efficient.
2) [Sentences Are Not Always Best Approach]

It slows you down. Makes it less likely you will do it right if it takes you longer.

3) [Pictures and diagrams]

4) [Definitions of abbreviations or symbols]

5) [Photos or videos ]

These are often very useful.

6) [What you did vs. what you planned to do]

7) [Accent Important Things]

8) [Organize the Page]

Wrap Up (2 minutes)

-Go through these.

1) [table of contents]

Though it might seem silly to have one while you notebook only has 5 completed pages, it is far from silly when your notebook has hundreds of pages. Also, either clearly label the pages with numbers or dates.

2) [msitakes? mistakes]

This is the appropriate way to deal with mistakes. Do not erase or scribble out.

About Grading (1 to 2 minutes)

-Say something like

"I will collect these at the end of every lab session and return them to you by your next lecture class. Each time I will not read everything for that week, but instead will look for three to six pre-decided secret items to grade. This will usually take me less than a minute, but if it takes me more than two, that indicates your notebook is poorly organized, and you will not earn the corresponding points.

As the semester progresses, each week's assignment will be worth more points. For example, for the first few weeks your notebooks will be worth 3 points each week, and in the final weeks, they'll be worth 6 points per week. Often students are disappointed in the their performance early on, but do rather better later.

How should you keep a notebook? What should you keep in mind? All these things we said here. If you keep these motivations and strategies in mind, you'll learn this valuable skill. There are also very explicit instructions in the lab manual, but that only gives one way of many to keep a good lab notebook." 


\section{Acknowledgments}

Thank you to Mike Brown, EJ Crane, Fabien Jammes, Karl Johnson, Sara Olson, Melissa Petreaca Ruben Petreaca, and Rou-Jia Sung for their help and insights into these exercises over the years.
About the Authors

Jonathan Moore has been as assistant professor of biology and lab coordinator at Pomona College since 2012, where he teaches mostly introductory courses in genetics and cell biology.

Theresa Lynn has been a professor of physics at Harvey Mudd College since 2006, where she teaches across the breadth of their curriculum and researches quantum information. 


\section{Mission, Review Process \& Disclaimer}

The Association for Biology Laboratory Education (ABLE) was founded in 1979 to promote information exchange among university and college educators actively concerned with teaching biology in a laboratory setting. The focus of ABLE is to improve the undergraduate biology laboratory experience by promoting the development and dissemination of interesting, innovative, and reliable laboratory exercises. For more information about ABLE, please visit http://www.ableweb.org/.

Advances in Biology Laboratory Education is the peer-reviewed publication of the conference of the Association for Biology Laboratory Education. Published articles and extended abstracts are evaluated and selected by a committee prior to presentation at the conference, peer-reviewed by participants at the conference, and edited by members of the ABLE Editorial Board. Published abstracts are evaluated and selected by a committee prior to presentation at the conference.

\section{Citing This Article}

Moore JE, Lynn TW 2020. Lab notebooks: efficient grading and effective learning. Article 45 In: McMahon K, editor. Advances in biology laboratory education. Volume 41. Publication of the 41st Conference of the Association for Biology Laboratory Education (ABLE). https://doi.org/10.37590/able.v41.art45

Compilation (C) 2020 by the Association for Biology Laboratory Education, ISBN 1-890444-17-0. All rights reserved.

No part of this publication may be reproduced, stored in a retrieval system, or transmitted, in any form or by any means, electronic, mechanical, photocopying, recording, or otherwise, without the prior written permission of the copyright owner.

ABLE strongly encourages individuals to use the exercises in this volume in their teaching program. If this exercise is used solely at one's own institution with no intent for profit, it is excluded from the preceding copyright restriction, unless otherwise noted on the copyright notice of the individual chapter in this volume. Proper credit to this publication must be included in your laboratory outline for each use; a sample citation is given above. 